Ann. rheum. Dis. (1966), 25, 688

\title{
ALLOPURINOL THERAPY OF GOUT WITH RENAL COMPLICATIONS
}

\author{
BY \\ KARL-HOLGER SJÖBERG \\ Department of Medicine, County Hospital, Mölndal, Sweden
}

Although probenecid is an excellent drug, and has enabled many patients to escape invalidism, and has probably reduced the incidence of kidney damage caused by gout, this and similar drugs often have no effect in patients with renal insufficiency. Allopurinol has been proved to produce a striking reduction in serum uric acid (SUA) and urinary uric acid (UUA). Because it is of great interest to know whether allopurinol can prevent continued kidney damage or eventually improve already impaired renal function, we have tried it in ten male patients with gouty kidney involvement. Two of them, 28 and 45 years of age, had a very severe form of gout and died 2 weeks and 11 months respectively after starting allopurinol treatment. The other eight patients had slight to moderate renal insufficiency with serum creatinine of 1.5 to $3.5 \mathrm{mg}$. $/ 100 \mathrm{ml}$.; one of these men died of cerebral haemorrhage. The average duration of treatment was 5 to 6 months (range 2 weeks to 18 months).

In the patients with severe gouty kidney involvement allopurinol did not seem to change the course of the disease.

The condition of a 45-year-old man, who received allopurinol for 11 months, deteriorated at the same rate in spite of reduction of the SUA and UUA. After 5 months the allopurinol was discontinued for a time, but widespread soft tissue calcification developed especially in the chest wall (Fig. 1). This calcification was probably caused by secondary hyperparathyroidism, because the patient in the terminal stage of the disease showed high calcium and phosphorus levels in the blood. No xanthine or uric acid could be traced in the calcified tissues post mortem and the kidneys were small with microscopic appearance typical of that seen in gout.

In those with moderate kidney failure good results were obtained and after a time the gouty attacks decreased or almost disappeared. Kidney function did not change during allopurinol treatment except in one patient who showed signs of improvement.

This 47-year-old man had a severe tophaceous gout which had started 25 years previously, and nephrocalanosis, probably from probenecid which he received for
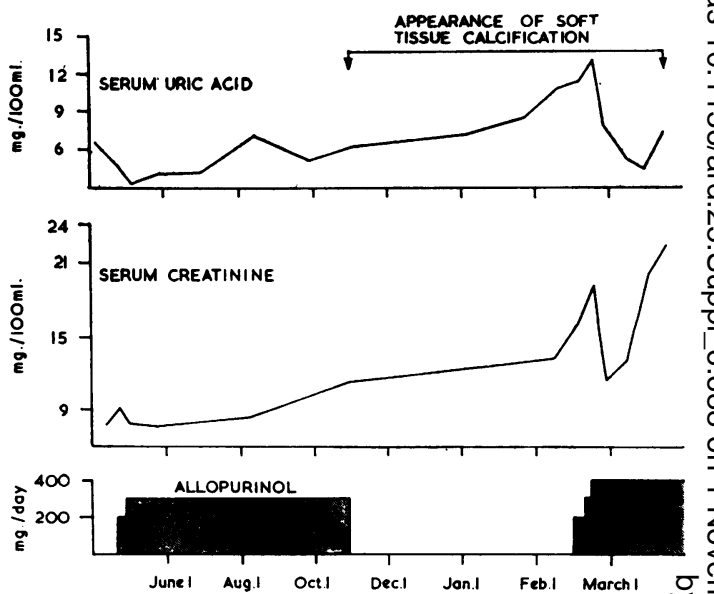

Fig. 1.-A 45-year-old man who had a very severe form of gout with impaired renal function for 10 years.

10 years from 1952-62. Since then two attempts had $\overrightarrow{0}$ been made to start with probenecid again but on bertion occasions hypercalcaemia and increasing serum creatinifie. developed (Figs 2 and 3, opposite). Careful examinations were made to detect whether the patient had hyperparathyroidism or not, but as far as we could determine the function of the parathyroid glands was normal. When allopurinol treatment was started in December, $\stackrel{\mathrm{D}}{\mathrm{Q}}$ 1964, a slow improvement of kidney function set in and $\stackrel{\varrho}{\square}$ inulin clearance increased from $31 \mathrm{ml} . / \mathrm{min}$. in Novem- $\overrightarrow{\vec{O}}$ ber, 1963 , to $70 \mathrm{ml} . / \mathrm{min}$. in April, 1966 (Table). SUA 3 and UUA levels fell but no change was observed in the tophi. At the beginning of treatment seven renalo stones containing calcium and uric acid but not xanthine appeared in the urine. Also in April, 1966, when the dose of allopurinol was increased to $600 \mathrm{mg}$./day, three additional renal stones of the same composition were passed in the urine.

TABLE
INULIN CLEARANCE IN A PATIENT WITH

NEPHROCALCINOSIS

\begin{tabular}{c|c|cc}
\hline \multicolumn{1}{c|}{ Date } & $\begin{array}{c}\text { Inulin } \\
\text { Clearance } \\
\text { (ml./min.) }\end{array}$ & $\begin{array}{c}\text { Duration of } \\
\text { Allopurinol } \\
\text { Therapy (months) }\end{array}$ \\
\hline $\begin{array}{c}\text { November, 1963 } \\
\text { February, 1965 } \\
\text { April, 1966 }\end{array}$ & 31 & -1 & O \\
\hline
\end{tabular}

The total urinary nitrogen was also determined in a patient who was in the hospital for two 6-month periods and took a constant low protein diet. There seemed to 

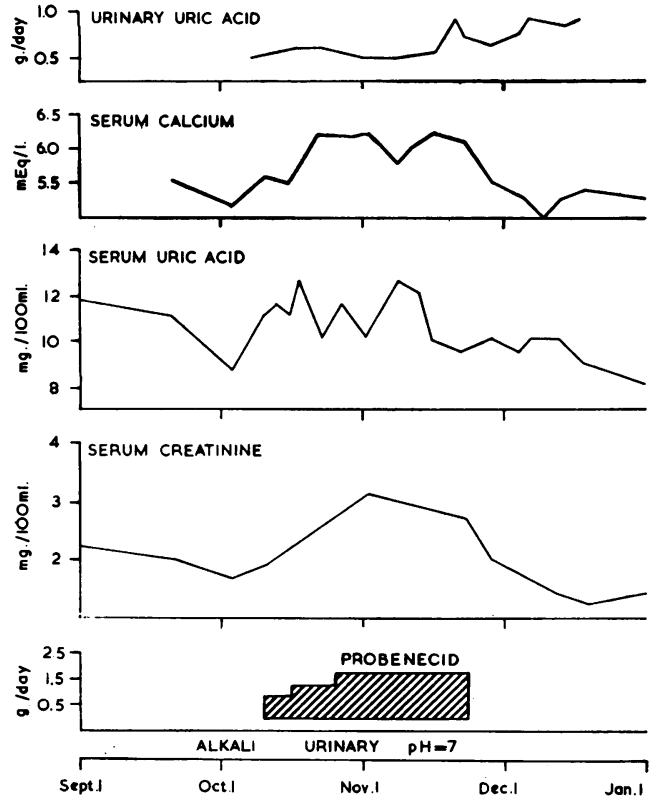

Fig. 2.-A 47-year-old man who had nephrocalcinosis, probably caused by probenecid. In a trial with probenecid hypercalcaemia and increasing serum creatinine developed.

be a correlation between the dose of allopurinol and urinary nitrogen content (Fig. 4). The fall in April, 1966, was unexpected but could have been due to a gouty attack at the same time or possibly to a renal stone which appeared in the urine a few days later. The highest values of total urinary nitrogen were obtained with a dosage of $400 \mathrm{mg}$. allopurinol per day and perhaps this was the optimal dose for the patient. The cause of the increase in urinary nitrogen was not found, in spite of determining urea, ammonia, and creatinine at the same time.

Calcium-phosphorus metabolism was examined carefully in this patient and in one other, because of the following observations:
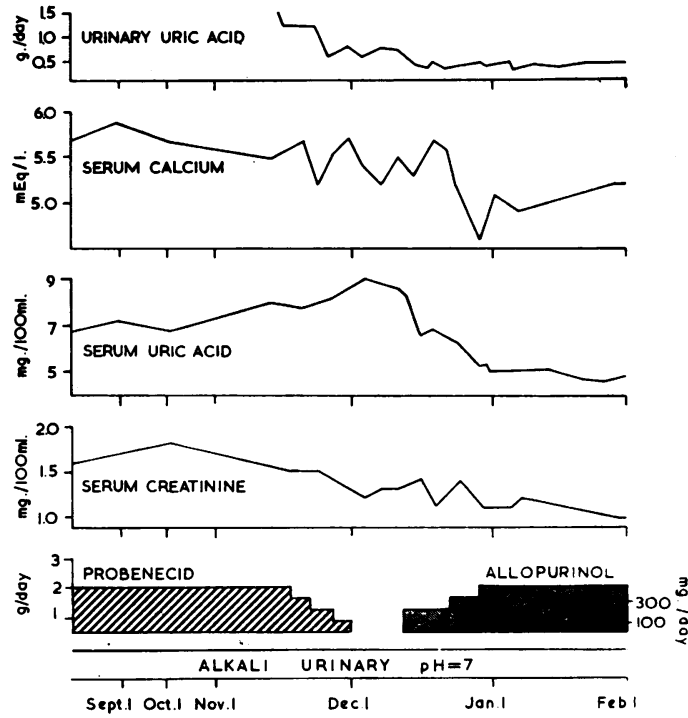

Fig. 3.-In another trial with probenecid the patient shown in Fig. 2 showed high values for serum calcium and serum creatinine but this
time serum calcium did not fall to normal until he had received allopurinol for some weeks.

(1) When probenecid treatment was interrupted for the second time in the patient with nephrocalcinosis the $\vec{\theta}$ serum calcium remained high, but it became normal aftej treatment with allopurinol for some weeks (Fig. 32. (Could the patient in spite of all earlier examinations of calcium-phosphorus metabolism have hyperparathyroidism and was the improved kidney function caused by lowering of serum calcium?)

(2) The appearance of ten calcium urate stones in the same patient after beginning allopurinol treatment.

(3) The appearance of widespread soft tissue calcification in one patient simultaneously with the interruption of the allopurinol treatment (Fig. 1).

(4) Many authors have observed a connexion between gout and hyperparathyroidism.

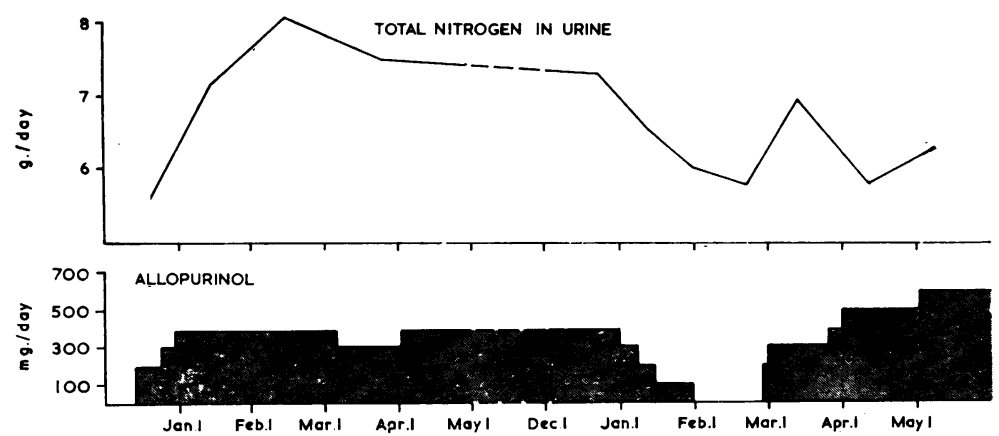

Fig. 4.-Total nitrogen in urine in a patient who was hospitalized on two occasions each lasting about 6 months. He received a low protein diet throughout. 


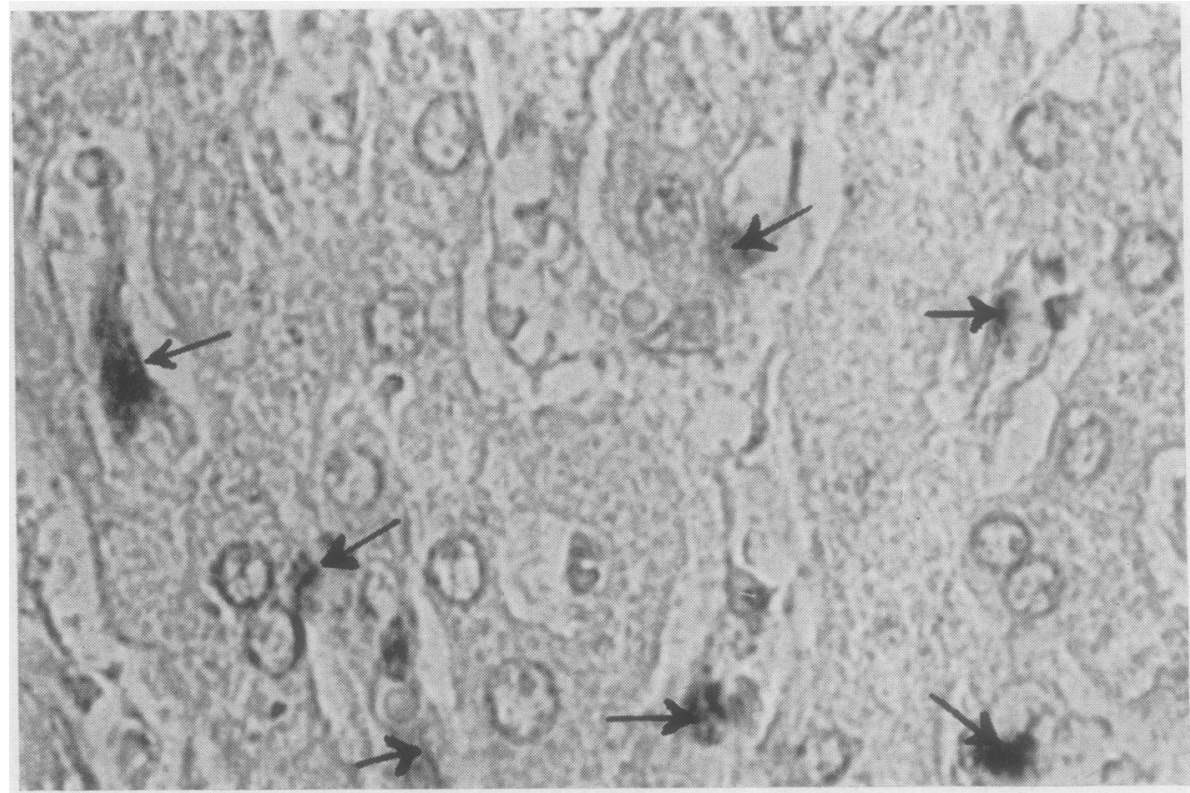
areas contained iron pigment. The liver cells were free from iron. $\times 250$.

When allopurinol treatment was discontinued in the patient with nephrocalcinosis, no change in the normal serum calcium was observed. A short trial in a patient with hyperparathyroidism was also carried out but the serum calcium remained high. Thus allopurinol probably had no effect on calciumphosphorus metabolism in these two trials, but further studies would probably be interesting.

As mentioned, three patients died during treatment (two in uraemia and the third from cerebral haemorrhage) after having taken allopurinol for 2 weeks, 2 months, and 11 months respectively. In the last patient a careful microscopic examination revealed increased hepatic iron pigment in the reticulo-endothelial cells of the liver, but there was no proliferation of the connective tissue and no inflammatory cells (Fig. 5). This patient had been treated intermittently with low doses of iron and had received five blood transfusions in the final stage of the disease. The serum iron was normal.

Because we considered this observation remarkable we carried out a liver biopsy in the patient who received allopurinol for 18 months with iron therapy periodically during this time; the liver was quite normal and no iron could be traced.

Allopurinol proved to be a well-tolerated drug and none of the patients developed any gastrointestinal or dermatological symptoms, although several had gouty attacks at the beginning of treatment and when the dose was increased. Colchicine used as a prophylaxis seemed to relieve the attacks bup one patient with moderate kidney impairment hado such severe attacks that the treatment was stopped after some weeks. One patient's psoriasis possibify became worse during treatment.

Repeated blood counts were carried out in $\frac{0}{4} \mid P$ patients and in one a reticulocytosis of 2 per cent? was observed. Serum iron and serum iron-binding capacity were normal in all cases. During treatment bilirubin, transaminases, and alkaline phosphatase levels as well as the thymol reaction were estimated $\stackrel{\mathbb{Q}}{\mathbb{D}}$ and no obvious changes were observed.

On the whole our experience with allopurinol was very satisfactory, and a considerable improvemen of kidney function was seen in one patient who die. not tolerate probenecid. The increased hepatic irop in one patient could be a coincidence, but I propose to carry out further examinations of the iron absorp 3 . tion in the intestine and iron deposition in the liver and elsewhere during allopurinol treatment. I alsg think that one should be careful of giving iron therapy to such patients until more is known about their iron metabolism.

I am indebted to my chief, Dr. G. Welin, for his help and advice during this trial. I wish to thank Dr. B? Hood, University of Gothenburg, for his co-operation. If am also indebted to Drs. T. Hanley and A. D. Munrod Faure, Burroughs Wellcome, for information about allo purinol, and to Burroughs Wellcome for supplies of allopurinol. 